\title{
Personality Dimensions And Measures Of Risk Tolerance: Variance/Skew And Scenario Response Assessment
}

\author{
Greg Filbeck, Penn State Behrend, USA \\ Patricia Hatfield, Bradley University, USA \\ Philip Horvath, National City Bank and Bradley University, USA
}

\begin{abstract}
In this paper, we explore the relationship between dimensions of the Myers-Briggs Type Indicator (MBTI) and individual investor ex-ante risk tolerance. Ex-ante risk tolerance is measured using ex-ante variance and skew tolerance measures as well as industry-like Scenario Response Assessment (SRA). Our study uses survey results to relate these measures of ex-ante risk tolerance to MBTI measures. Our results indicate that personality dimensions do explain many SRA measures of individual ex-ante risk tolerance and further suggest that the relationship between personality dimensions and the industry-like individual ex-ante risk tolerance measures are generally complex and non-linear in form. Finally, our results find fewer, but still complex and non-linear, relationships between variance/skew ex-ante risk tolerance measures.
\end{abstract}

Keywords: Portfolio Choice; Investment Decisions

\section{INTRODUCTION}

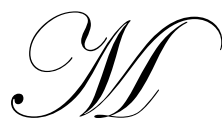

aking appropriate investment choices for investors become more complicated with the passage of time. O'Brien (2006) cites research from Cerulli Associates' Intermediary Markets Quantitative Update indicating that the number of mutual funds increased by more than 300 from 2004 to 2005, to a total of 16,580. According to the 2005-2006 Annual 401(k) Benchmarking Survey, conducted by Deloitte Consulting LLP (Deloitte Consulting), the International Foundation of Employee Benefit Plans, and the International Society of Certified Employee Benefit Specialists, pension plans offer an average of 17 investment options, compared to less than 13 in their 2004-2005 survey. (http://www.deloitte.com/dtt/press_release/0\%2C1014\%2Ccid\%25253D124461\%2C00.html). It is the job of the financial planner to help investors choose those funds that align the risk tolerance of the investor with the risk of the fund. In order to accomplish this, Scenario Response Assessment (SRA) surveys, which consist of individual responses to hypothetical situations, are generally used to measure the risk tolerance of the investor.

Our results indicate that personality dimensions may explain many SRA measures of individual ex-ante risk tolerance. Our results further suggest that the relationship between personality dimensions and the industry-like individual ex-ante risk tolerance measures are generally complex and non-linear in form. Finally, our results find fewer, but still complex and non-linear, relationships between variance/skew ex-ante risk tolerance measures, personality dimensions, and SRA measures. Taken together our results suggest that industry measures of ex-ante risk tolerance are capturing the individual's personality rather than individual ex-ante risk tolerance.

\section{EXISTING LITERATURE}

A number of studies examine various ways of measuring ex-ante risk tolerance for individual investors. Empirical evidence indicates ex-ante risk tolerance may be measured by examining factors such as age, education, income, wealth, and marital status among individuals (Riley and Chow, 1992; Schooley and Worden, 1999). Others studies investigate issues related to discerning individual risk tolerance based on the proportion of wealth allocated 
to risky assets (Cohn, Lewellen, Lease, and Schlarbaum, 1975; Friend and Blume, 1975; Lease, Lewellen and Schlarbaum, 1974; Siegal and Hoban, Jr., 1982). Riley and Chow (1992) find an inverse relationship between risk aversion and the demographic factors of education, income, and wealth levels. They also find that risk aversion decreases with age until the period five years prior to retirement, where risk aversion reverses direction and increases with age. Schooley and Worden (1999) find that investors with post-secondary educations held higher percentages of their portfolios in equity securities. Married couples hold higher percentages of the portfolios in equity than singles. Percentage of equity in a portfolio increases with age until retirement and then decreased with age.

A variety of investor personality profiles exist to explain investor preferences. Bailard, Biehl and Kaiser (1986) classify investors into five categories: adventurers, celebrities, individualists, guardians, and straight arrows based on two personality characteristics. The first characteristic represents a continuum of the careful personality versus the impetuous personality, and the other axis is based on a continuum of an anxious versus confident personality. Each of the five categories is shown to imply a different risk tolerance. Barnewall (1987) offers a model of classifying differences in risk aversion based on the notion that individuals are either passive or active, careful/impetuous, and anxious/confident, respectively. Previous empirical evidence indicates that investors tend to be more risk averse as they near and pass retirement, with less education, and with less wealth (Riley and Chow, 1992; Schooley and Worden, 1999).

The MBTI is a widely used personality indicator for the purpose of bettering understanding personality preferences and differences [see Keirsey and Bates, 1978; Lawrence, 1994; McCaulley, 1976; Myers, 1979, 1980; and Myers and McCaulley, 1998]. The MBTI questionnaire measures the strength of individuals' preferences on four dimensions that indicate (1) where individuals prefer to focus their attention (extraversion versus introversion), (2) how they acquire information about their surroundings (sensing versus intuition), (3) how they make decisions (thinking versus feeling), and (4) how they orientate to the environment (judging versus perception). The four scales of the MBTI appear in Exhibit 1.

The breakdown by dimension in the general U.S. population is approximately 75 percent extroverted (E), 25 percent introverted (I), 75 percent sensing (S), 25 percent intuitive (N), 50 percent thinking (T), 50 percent feeling (F), 55 percent judging (J), and 45 percent perceiving $(\mathrm{P})$. With the exception of the thinking/feeling preference ([2/3 of males prefer thinking and 2/3 of females prefer feeling (Myers and McCaulley, 1998]), there are no gender-based differences in type. From these four dimensions of the MBTI, a total of sixteen combinations emerge. For example, an individual whose preferences indicate a combination of INTP would tend to draw his or her energy from internal forces (I), process information based on possibilities and hunches $(\mathrm{N})$, make decisions based on logic and reason (T), and prefer a flexible, adaptive environment $(\mathrm{P})$. While sharing basic personality characteristics, two individuals with the same type may vary widely in their application because of experiences, maturity, and environment.

A study by Filbeck, Hatfield, and Horvath (2005) examines the relationship between personality dimensions, as measured by the Myers-Briggs Type Indicator (MBTI) scores (MBS) and ex-ante risk tolerance, as measured by variance and skew. When using linear regression, no significant relationships are detected. However, when using bi-variate analysis, they find that there is a significant relationship between some personality dimensions and ex-ante risk tolerance.

The bi-variate results indicate that variance is a function of the Thinking $(\mathrm{T}) /$ Feeling $(\mathrm{F})$ and the Judging $(\mathrm{J}) /$ Perceiving $(\mathrm{P})$ personality dimensions. The stronger the preference for thinking on the T/F dimension, the higher the tolerance for variance. As the thinking preference score declines, the tolerance for variance declines sharply at first, and then continues to decline, but at a slower rate as MBS move toward the middle of the T/F dimension. Tolerance for risk is at a minimum for individuals with equal preferences for thinking and feeling and any preference on the feeling side of the dimension. With respect to the $\mathrm{J} / \mathrm{P}$ dimension, results indicate that as preferences MBS grow stronger for the judging preference, the tolerance for variance increases exponentially. Individuals with strong perceiving preferences have virtually no tolerance for variance.

Their findings also suggest that ex-ante risk tolerance as measured by skew is a function of the $\mathrm{T} / \mathrm{F}$ and the 
Sensing (S)/Intuition (N) personality dimensions. As the preference score for thinking decreases, tolerance for upside or downside potential diminishes. The relationship of skew to $\mathrm{S} / \mathrm{N}$ is cubic. This result indicates that those with higher preferences for the sensing have a higher degree of skew tolerance. Once preference MBS cross to intuition, skew tolerance rapidly diminishes. This research suggests that there are personality characteristics that may be used to assess ex-ante risk tolerance of an individual.

In summary, there are several studies that suggest various ways of assessing risk tolerance. However, no study exists that examines the surveys that are used by brokers and financial planners in an attempt to measure exante risk tolerance. This study contributes to the existing literature by examining how effectively the SRA measures currently used by brokers and financial planners measure an individual's ex-ante risk tolerance. Our findings suggest that they are not effective in assessing an individual's ex-ante risk tolerance but rather are complex surrogates for individual personality dimensions; and, perhaps, investors would be best served by using one of the other methods previously described in the empirical studies.

\section{SAMPLE AND METHODS: VARIANCE, SKEW}

Our sample consisted of a survey of 68 individuals that includes college students and adults from a variety of demographic factors and various levels of investment experience. The age distribution of the participants is approximately normal with a mean age of 30.16 years and a median age of 30 years. Twenty-seven percent of the respondents were female. Twenty-four percent of the participants considered themselves to be sophisticated investors while the remaining 76 percent considered their investment skills to be average or below-average. The participants were given the MBTI along with our ex-ante risk tolerance survey, which appears as Exhibit 2 in the appendices. The purpose of this study is to consider the relationships between the MBTI personality dimensions and individual ex-ante risk tolerance as measured from the survey results. One part of the survey directly captures the distribution of returns, cumulative probabilities, acceptable to each individual. The variance $\left(s^{2}=\sum_{i}\left(r_{i}-E(r)\right)^{2} \operatorname{Pr}\left(r=r_{i}\right)\right)$ and relative skew (for our purposes:

relative skew $\left.=\left[\sum_{i}\left(r_{i}-E(r)\right)^{3} \operatorname{Pr}\left(r=r_{i}\right)\right] / s^{2}\right)$ were then calculated for each respondent. This approach hereafter is referred to as the Moments Approach (MA). The survey also (section 2 of the Exhibit 2) provides indicators of ex-ante risk tolerance using measures similar to those commonly applied to the assessment of ex-ante risk tolerance in practice: SRAs. Exhibit 3 in the appendices reflects the implicit classification of ex-ante risk tolerance based on responses to these questions as interpreted and confirmed by several practitioners. These practitioners held either the Certified Financial Planner (CFP) or Certified Financial Analyst (CFA) designation and/or were broker-dealer registered representatives. The MBTI dimension scores are determined using Form M of the MBTI consisting of 93 questions.

In order to focus on the relationship between personality type and ex-ante risk tolerance, we control for a number of demographic and personal variables that may impact ex-ante risk tolerance. These controls include net worth (NW), income (IN), the level of investor self-perceived sophistication (S), marital status (M), number of dependents (Dep), age (Age), gender (G), years with a company (Yrs) and level of education (Ed). Following Filbeck, Hatfield and Horvath (2005), a factor analysis of the controls is conducted to eliminate joint effects and reduce these data to a number of orthogonal variables for later use in regression analysis (see: Hair, Anderson and Tatham, 1970, 235). The exploratory, principal components factor analysis, under varimax rotation, resulted in three factors:

Control Factor $1=0.742(\mathrm{NW})+0.752(\mathrm{IN})+0.612(\mathrm{M})+0.830(\mathrm{Dep})+0.868($ Age $)+0.782($ Yrs $)$

Control Factor $2=-0.606(\mathrm{~S})+0.862(\mathrm{Ed})$

Control Factor $3=0.867(\mathrm{G})$

We describe Control Factor 1 as the "wealth" factor, Control Factor 2 as the "sophistication" factor, and Control Factor 3 as the "gender" factor. Here and below we chose to incur the statistical cost of identifying too many factors as opposed to too few factors that would have been the result of applying any of the several techniques that 
may be used in factor identification (see: Rummel, 1970, 354, 367). This is particularly appropriate as we lent no interpretation to the factor loadings per se other than to generate as many inter-orthogonal variables as practicable.

\section{RISK TOLERANCE: SRA MEASURES}

Responses to the SRA Questionnaire (shown in Exhibit 3) were coded on a one (very risk tolerant) to five (very risk intolerant) point scale as follows:

\section{QUESTION \#}

$1,5-10,12,14$

$2-4,11,13$
STRONGLY AGREE

1

5

\section{STRONGLY DISAGREE}

5

1

Responses were rescaled to provide consistency of direction of agreement. The rescaled response scale is non-metric. In general, classical statistical approaches are not appropriate for non-metric data; thus, non-parametric statistical measures are used. We find no support in the literature indicating how these responses to the SRA are to be used in providing a consistent metric to assess ex-ante risk tolerance across individuals. Further, there is available to us no reliable anecdotal evidence in support of any combination of these response variables in the assessment of ex-ante risk tolerance. Thus, response values normalized to reflect consistent directionality provide the basis for the computation of the following summary measures for each respondent, $\mathrm{t}$ :

CUMULATIVE RESPONSE $\mathrm{t}_{\mathrm{t}}=$ sum of response value for individual $\mathrm{t}$

MEDIAN RESPONSE $_{\mathrm{t}}=$ median response value for individual $\mathrm{t}$

MODE RESPONSE $E_{t}=$ modal response value for individual $t$

VARIANCE RESPONSE $_{\mathrm{t}}=$ variance of response value for individual $\mathrm{t}$

RANGE RESPONSE $_{\mathrm{t}}=$ range of response value for individual $\mathrm{t}$

These statistical representations may provide differing manifestations of SRA ex-ante risk tolerance and insight into the relationship between ex-ante risk tolerance and personality type. For instance, an individual with a higher cumulative response may be said to be more risk tolerant than another with a lower cumulative response. Median and modal responses are non-parametric measures of central tendency that will differ if there is skew in the distribution of responses; and, as such, higher values might differ and may indicate higher degrees of ex-ante risk tolerance. The dispersion, variance, of responses may also be positively related to increased ex-ante risk tolerance as would the range of responses.

Further, the coded and rescaled (for consistency of direction) responses for respondents to the 14 questions in the ex-ante risk tolerance survey, SRA, (shown in Exhibit 3) are subjected to exploratory, principal components factor analysis under varimax rotation to provide respectively independent ex-ante risk tolerance indicators (see: Hair, Anderson and Tatham [1987] p. 235 and Rummel [1970] p. 354, 367). There are six factors constructed using the rule that each question is assigned to the factor in which it had the highest loading and that no variable was included in a factor with a loading of less than 0.50 . The factors are typified as follows:

- $\quad$ Dividend/Portfolio Preference $=0.92(\mathrm{Q} 11)+0.636(\mathrm{Q} 12)+0.785(\mathrm{Q} 13)+0.567(\mathrm{Q} 14)$

- $\quad$ Current Position = 0.683(Q5)+0.840(Q6)

- $\quad$ Recent Stability $=0.728(\mathrm{Q} 2)+0.684(\mathrm{Q} 3)+0.451(\mathrm{Q} 4)-0.594(\mathrm{Q} 8)$

- $\quad$ Knowledge $=0.834(\mathrm{Q} 1)$

- $\quad$ Predictive Confidence $=0.815(\mathrm{Q} 7)-0.555(\mathrm{Q} 9)$

- Company Image $=0.912(\mathrm{Q} 10)$

For instance, if the individual scores higher on Dividend/Portfolio Preference, that person exhibits greater tolerance for risk than otherwise. Likewise, a person who scores low on Current Position exhibits a different ex-ante risk tolerance than one who has a higher Current Position score. A person scoring low on Recent Stability is less risk tolerant to increasing recent instability in prices. A person who scores high on Knowledge is likely to be more risk 
tolerant than otherwise as another who has a high Predictive Confidence score. Finally, a higher score on Company Image represents greater tolerance to risk.

\section{RESPONSE VALUE RESULTS}

Ordinary least squares multiple regression of these six resulting factors each on the four MBS. These six multiple regressions provide no significant linear relationships. Here and below, no power tests are conducted. It is plausible that there could, in fact, be relationships between the any or all of the MBS and any or all of the six response factors and our findings may be the result of sampling error.

Next, we apply bivariate curve estimation for each of the five summary statistics on the four MBS factors and subsequently we apply bivariate curve estimation for the six response factors on each of the four MBS factors. With regards to exploration of relationships between the five SRA summary statistics and the personality dimensions reflected in the MBS a total of 20 bivariate curve estimations are conducted for goodness of fit with 11 different functional relationships (linear, log, inverse, quadratic, cubic, power, compound, S, logistic, growth, and exponential functions). Of these 220 tests, three provided significant results. Significant results are:

Median Response $_{t}=\exp \left(0.979-\frac{0.847}{\mathrm{MBS1}}\right)$

Individual median response on the SRA questionnaire is related to MBS1 (Thinking/Feeling score). This relationship is significant at or better than the 0.10 level with a p-value of 0.0330 . The form of the relationship is that of an "S" function. (Copies of this manuscript with figures provided illustrating each relationship may be obtained by contacting any author).

By the SRA measure, median response, ex-ante risk tolerance is related in a complex non-linear manner to MBS1 (Thinking/Feeling score). An individual with a feeling preference has a great deal of tolerance for risk. Tolerance for risk then increases slightly as preference scores moves marginally from the feeling preference to the thinking preference, then decrease at a decreasing rate over the remainder of the continuum. Individuals with the thinking preference are seen by this relationship to be more intolerant of risk than those with a preference for feeling, but care must be taken as the relationship is not consistently increasing over the whole spectrum from feeling to thinking.

Similarly the Modal response by each individual is explained by MBS3 (Judging/Perceiving score) and is significant at the 0.10 level with a p-value of 0.0640 as follows.

Mode Response $=2.0766+\frac{8.6664}{\mathrm{MBS3}}$

The form of the relationship follows an Inverse function. This relationship suggests that the level of exante risk tolerance increases at a decreasing rate as the individual is classified on a continuum from a "purely" perceiving preference to a "purely" judging preference. An individual with a preference for perceiving is relatively less risk tolerant that an individual with a preference for judging.

An inverse functional relationship also explains the $t^{\text {th }}$ individual's range of responses on the SRA measure employed by broker-dealers. The relationship is significant at the 0.10 level with a p-value of 0.0020 . The relationship is given by:

\section{Range Response $=6.3392+0.0563 \mathrm{MBS} 1$,}

In a manner similar to that of MBS3 (Judging/Perceiving score) ex-ante risk tolerance increases from relatively high for investors with a sensing preference and increases at a decreasing rate over the continuum to those 
investors with an intuition preference. Those individuals with a very strong preference for intuition are, overall, more risk tolerant than those with a very strong preference for sensing.

\section{SRA FACTOR GENERATED RESULTS}

Continuing with an analysis of the SRA factors generated above six response factors each were tested for each of the 11 bivariate nonlinear relationships with each of the four MBS factors for a total of 264 tests. Of these tests, nine were found to be significant; significant results are:

Dividend/Portfolio Preferences are linearly related to MBS1 (Thinker/Feeler score) at the 0.10 level of significance with a p-value of 0.0030 as follows:

Dividend/Portfolio Preference $_{\mathrm{t}}=6.3392+0.0563 \mathrm{MBS}_{\mathrm{r}}$

Figure 6

RF1: Dividend/Portfolio preference and MBS4: Sensing/Intuition

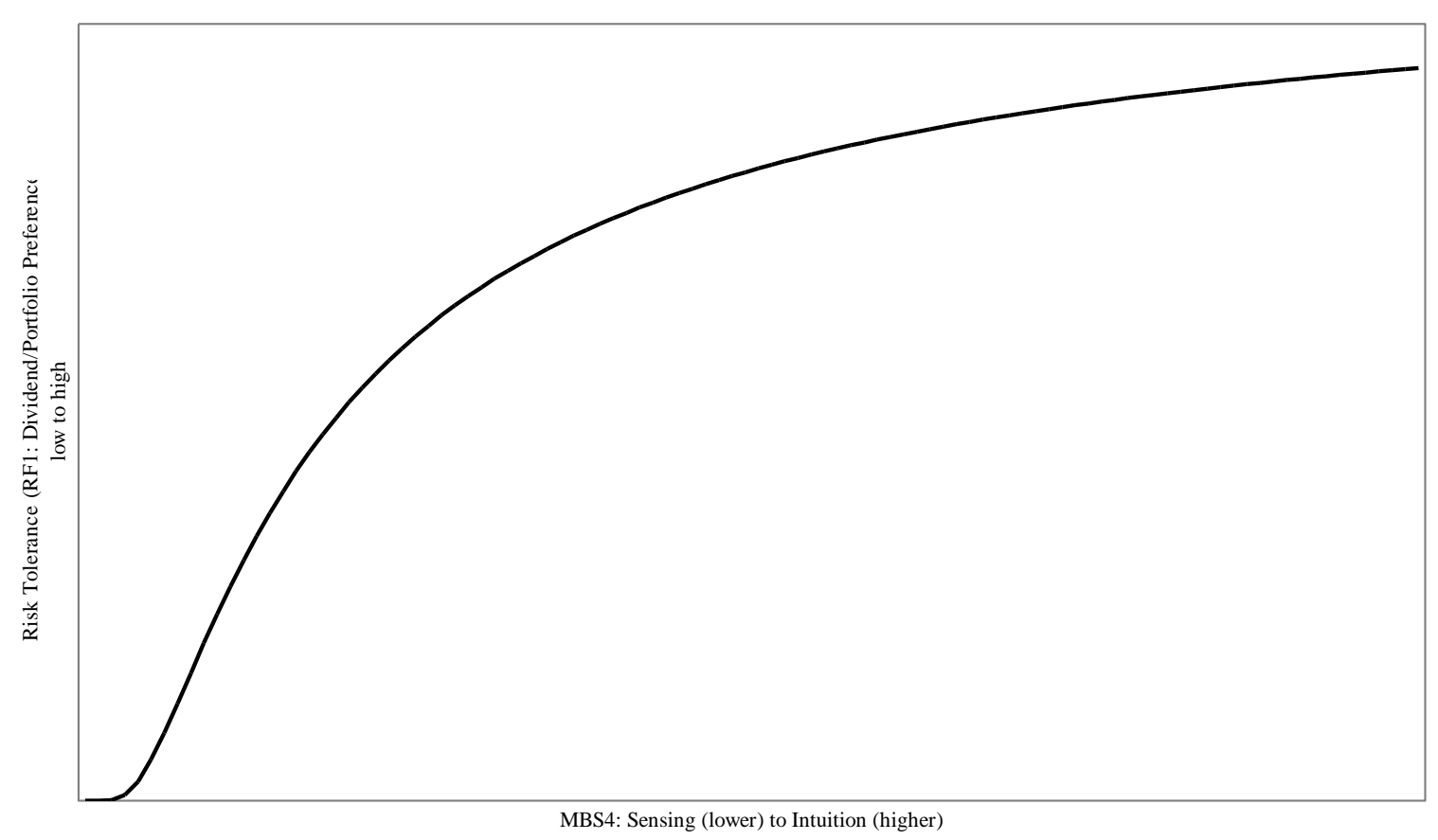

Dividend/Portfolio Preference is influenced by MBS3 (Judging/Perceiving score) in addition to the influence of MBS1 immediately above. The model:

Dividend/Portfolio Preference $_{t}=8.8782-0.3467 \mathrm{MBS}_{\mathrm{t}}+0.00176 \mathrm{MBS}_{\mathrm{t}}^{2}-0.0002 \mathrm{MBS}_{\mathrm{t}}^{3}$

is cubic in form. The influence is significant at the 0.10 level with a p-value of 0.0880 .

A model of the form:

Dividend/Portfolio Preference $_{1}=\exp \left(2.0677+\frac{1.5182}{\text { MBS4 }}\right)$ 
which is an "S" function further influences an individual's Dividend/Portfolio preferences but now as related to the individual's Sensing/Intuition score. This relationship is significant at the 0.10 level with a p-value of 0.0010 .

The effects of Recent Stability scores on the individual's SRA ex-ante risk tolerance questionnaire are explained by individual's MBS1 (Thinking/Feeling score) according to an "S" function given by:

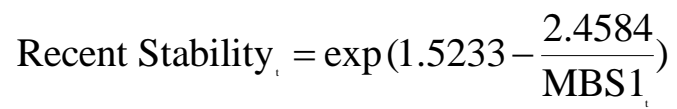

which is significant at the 0.10 level with a p-value of 0.0010 .

Further, Recent Stability scores are explained by MBS3 (Judging/Perceiving score) following the cubic function:

Recent Stability $_{\mathrm{t}}=9.23129-0.6269 \mathrm{MBS}_{\mathrm{t}}+0.0241 \mathrm{MBS3}_{\mathrm{t}}^{2}-0.0003 \mathrm{MBS3}_{\mathrm{t}}^{3}$

which is significant at the 0.10 level with a p-value of 0.0009 .

The sole personality influence on individual investor Knowledge score on the SRA ex-ante risk tolerance questionnaire used here is that of MBS3 (Perceiver/Judger score) and is of the "S" form which is significant at the 0.10 level with a p-value of 0.0460 :

Knowledge $=\exp \left(0.9313-\frac{5.0353}{\mathrm{MBS3}}\right)$

Likewise, individual Predictive Confidence has one personality explanatory variable: MBS2 (Introversion/Extroversion score). This relationship follows an exponential function:

Predictive Confidence $_{,}=3.4781 \exp \left(-0.0045 \mathrm{MBS}_{2}\right)$

This relationship is significant at the 0.10 level with a p-value of 0.0770 .

Company Image scores of individual respondents is affected by several of the personality measures. First, Company Image is linearly related to MBS2 (Introversion/Extroversion score) in a linear manner that is found to be significant at the 0.10 level $(\mathrm{p}$-value $=0.0660)$ and is given by:

\section{Company Image $=2.8021-0.0146 \mathrm{MBS} 2$}

Company Image scores for individuals on the SRA ex-ante risk tolerance test used by broker dealers is also functionally related to MBS3 (Judging/Perceiving score) in an inverse form that is significant at the 0.10 level and a p-value of 0.0160 given by:

Company Image $=2.0008+\frac{10.6583}{\mathrm{MBS3}}$ form:

Finally, the SRA ex-ante risk tolerance scores for individuals are explained by a quadratic function of the

$$
\text { Company Image }=1.8943+0.0571 \mathrm{MBS}_{\mathrm{t}}-0.0012 \mathrm{MBS}_{\mathrm{t}}^{2}
$$

significant at the 0.10 level with a p-value of 0.0760 . 


\section{INTERACTION OF MA WITH SRA MEASURES}

The SRA measures may be revealing individual ex-ante risk tolerance by indirectly capturing the ex-ante risk tolerance revealed in the MA. That is, the SRA may be a surrogate for variance or relative skew via a functional relationship. Each respondent summary measure (five measures) and respondent factor (six factors) is subsequently regressed on the variance and the scaled, normalized skew measures of ex-ante risk tolerance for a total of 22 ordinary least squares regressions. No significant relationships are found. However, there may be nonlinear relationships between the five summary measures, the six response factors, and the variance and skew measures. Each of the five summary measures is tested for fit with each of the 11 bivariate nonlinear curve estimations for a total of 110 tests; of these one was significant. The significant result is:

Mode Response $=1262174-\frac{575614}{\text { Skew }_{1}}$

an inverse function that is significant at the 0.10 level with a p-value of 0.0030 .

Each of the six SRA response factors was tested for fit with each of the 11 nonlinear functions using bivariate curve estimation as above for a total of 132 tests. Of these, three tests were significant: value of 0.000 )

Current Position is logarithmically related to variance tolerance (significance at the 0.10 level with a pCurrent Position $_{\mathrm{t}}=-5.927+0.2270 \ln \left(\right.$ Var $\left._{\mathrm{r}}\right)$

Recent Stability scores for individuals on the SRA risk questionnaire are explain in a logarithmic form to individual variance tolerance:

Recent Stability $=1.1963-0.1309 \ln ($ Var $)$

And, finally, individual Company Image scores reported on the SRA ex-ante risk tolerance questionnaire is linearly related to the MA risk measure Skew tolerance (significance is 0.10 level and a p-value of 0.0200 ) given by:

Company Image $=1.5214+9.2\left(10^{-7}\right)$ Skew

\section{RISK TOLERANCE, MBTI PERSONALITY, AND MA MEASURES}

MA measures of ex-ante risk tolerance are tested for relationships with MBTI score factors in a manner similar with that above for the SRA ex-ante risk tolerance indicators by Filbeck, Hatfield and Horvath (2005). Individual variance and skew measures each were tested for each of the 11 nonlinear relationships with each of the four MBS factors using bivariate curve estimation for a total of 88 tests. The bivariate, nonlinear tests had provided the three following statistically significant results:

$$
\text { Variance }_{t}=2.2\left(10^{12}\right) \mathrm{MBS}_{\mathrm{t}}^{-1.5926}
$$

which indicates that Variance is a function of MBS1 (Thinking/Feeling score and is significant at the 0.10 level with a p-value of 0.0080 .

Variance is similarly explained by an exponential function of MBS3 (Judging/Perceiving score):

$$
\text { Variance }_{t}=2.2\left(10^{9}\right) \exp \left(0.853 \mathrm{MBS}_{\mathrm{t}}\right)
$$


which is also significant at the 0.10 level and has a p-value of 0.0280 .

Skew is related to MBS1 (Thinking/Feeling score) and to MBS4 (Sensing/Intuition score). These relationships are respectively:

Skew $\left._{1}=923190+\frac{772404}{\text { MBS1 }}\right)$

and

Skew $_{\mathrm{t}}=1153586-3482 \mathrm{MBS}_{\mathrm{t}}+1934.5 \mathrm{MBS}_{\mathrm{t}}^{2}-28.813 \mathrm{MBS}_{\mathrm{t}}^{3}$

which are of the form inverse and cubic, respectively. Both are significant at the 0.10 level with p-values of 0.092 and 0.034 respectively.

\section{DISCUSSION}

Filbeck, Hatfield, and Horvath (FHH) (2003) find four material, nonlinear relationships where MA ex-ante risk tolerance measures, variance and skew, are explained by MBTI personality dimensions. The FHH result lends some support for the hypothesis that ex-ante risk tolerance determination could be aided by personality dimensions. If one finds that MBTI or some other personality dimension measurement instrument explains ex-ante risk tolerance, one or the other, but not both would be preferred.

SRA measures are much more consistent with MBTI personality dimensions than are the MA measures of variance and skew. Nine (9) relationships are highly nonlinear while four are linear. These results suggest that the measurement of an individual's ex-ante risk tolerance will need to be accomplished with a great deal of care. MBS1: (Thinking/Feeling score) suggests that ex-ante risk tolerance increases as the MBS1 dimension progresses from a preference for feeling to a preference for thinking for our SRA measures. However, this result is obtained over only a portion of the curve. This could provide conflicting conclusions regarding the ex-ante risk tolerance for an individual with a strong preference for feeling. MBS2: (Extroversion/Introversion score) consistently suggests decreasing ex-ante risk tolerance over the SRA measures tested. MBS3 provide conflicting indications of individual ex-ante risk tolerance on our SRA measures. An individual is suggested to become less risk tolerant as the personality dimension proceeds from a preference for perceiving to a preference for judging and ex-ante risk tolerance decreases at a decreasing rate. This same dimension suggests that ex-ante risk tolerance decreases then increases then decreases! The judging/perceiving dimension suggests that ex-ante risk tolerance increases over its range.

The results of the analysis of SRA ex-ante risk tolerance measures as functions of MA measures provide sketchy support for an argument that the SRA and MA measures are identifying the same ex-ante risk tolerance. Modal response of individuals, which have no relationship with any of the MBTI personality dimensions, has a suggested effect of increasing ex-ante risk tolerance at a decreasing rate, as skew tolerance increases. Skew tolerance from large negative preference to large positive preference shows evidence of a positive proportional increase in ex-ante risk tolerance as measured by Company Image. Variance tolerance suggests both a positive, increasing at a decreasing rate, influence on ex-ante risk tolerance and a decreasing at a decreasing rate signal on exante risk tolerance. These inconsistent and conflicting results bode ill for the ex-ante risk tolerance implications of our SRA measures.

Some MBTI personality dimensions provide generally conflicting signals as regards ex-ante risk tolerance within SRA measures used here. More damagingly, conflicting ex-ante risk tolerance is exhibited between SRA exante risk tolerance measures and MA measures. MBS1: (Thinking/Feeling score), conflicting over a narrow range provides that ex-ante risk tolerance increases over the range from a strong preference for thinking to a strong preference for feeling while the same MBTI personality dimension suggests that ex-ante risk tolerance as measured by skew decreases (nonlinearly) over a similar personality dimension range. 
Similarly, MBS3: (Judging/Perceiving score) suggests that ex-ante risk tolerance, in general, decreases nonlinearly while variance tolerance increases for the individual who prefers judging as opposed to one who perceives perceiving.

MBTI personality dimension sensing/intuition provides almost no consistent information relative to ex-ante risk tolerance for SRA measures, but suggests that one who possesses a preference for sensing would have a lower tolerance for skew than one who possesses a preference for intuition. MBTI personality dimension MBS2: (Extraversion/introversion score) testing provided no suggestion on either variance or skew tolerance but was linearly consistent over two SRA measures: ex-ante risk tolerance diminishes for those preferring extroversion over those who prefer introversion.

It remains important to note that the sample size used here is not, by some standards, large and that there remains a possibility that a number of the tests conducted here have a possibility of accepting the hypotheses that there is no relationship between the dependent and independent variables when, in fact, there very well may be. Noting the p-values of the results that were deemed significant above indicate a very low chance of having rejected the implicit null when it is true.

\section{CONCLUSIONS}

In this paper, we explore the relationship between dimensions of the Myers-Briggs Type Indicator (MBTI) and individual investor ex-ante risk tolerance. Our study uses Scenario Response Assessment (SRA) survey results to relate these measures of ex-ante risk tolerance to MBTI measures. We find that SRA measures reflect personality dimensions to a greater degree than do the Moments Approach (MA) measures for variance and skew. The influence of the personality dimensions is unclear, contradictory and confusing with respect to SRA measures. Any attempt to implement MBTI personality dimensions must incorporate the complex influences on ex-ante risk tolerance whether using MA or SRA measures. We also find that MA measures are not clearly related to MBTI dimension scores (we find only two relationships variance and two relationships for skew). Moreover, MA measures are not clearly related to SRA measures. They are likely measuring differing things.

In summary, we suggest that the relationship between personality dimensions and the industry-like individual ex-ante risk tolerance measures are generally complex and non-linear in form. We find fewer, but still complex and non-linear, relationships between variance/skew ex-ante risk tolerance measures. Thus, our results suggest that industry measures of ex-ante risk tolerance are capturing the individual's personality rather than individual ex-ante risk tolerance.

Additionally, since there appears to be no generally accepted procedure that clearly and consistently relates SRA responses to ex-ante risk tolerance additional work needs to be done to develop an appropriate standard; either an MA or some consistent, testable alternative.

\section{AUTHOR INFORMATION}

Dr. Greg Filbeck, CFA, FRM, CAIA joined the faculty at Penn State Erie, The Behrend College, in the Fall of 2006 and holds the Black Family Endowed Professorship of Insurance and Risk Management. Research studies are focused within the investments, portfolio management, and behavioral finance areas. In addition to ten years experiences in academia, he has seven years of experience as Senior Vice-President of Schweser, a division of Kaplan, Inc, where he headed the content and curriculum areas and started and led marketing and sales areas. Dr. Filbeck has trained candidates for the Chartered Financial Analyst (CFA) designation on a worldwide basis.

Dr. Patty Hatfield joined the faculty at Bradley University, Foster College of Business, in the Fall of 1990 and holds the Stephens Professorship of Risk and Insurance. Her research focus is in the area of capital budgeting, behavioral finance and risk management. She also conducts case research and publishes case studies in finance. She is heavily involved in executive education and conducts financial training modules to middle and upper level management for Fortune 100 companies in domestic and international locations. 
Dr. Philip A. Horvath is chair of the Department of Finance and Quantitative Methods, Foster College of Business Administration at Bradley University. He is the Robert T. Stevenson Jr./National City Bank Professor of Finance and Director of the Master of Science in Quantitative Finance program. His research currently focuses on financial modeling, financial effects of reverse logistics, portfolio and investor choice issues and behavioral finance in both securities and corporate finance. He has recently been CFO of several small firms, developed a De-Novo Broker Dealer/investment management firm and has widely consulted in the corporate, investment and forensic areas.

\section{REFERENCES}

1. Bailard, T, D. Biehl, and Ronald W. Kaiser. (1986). Personal MoneyManagement, $5^{\text {th }}$ edition, Chicago: Science Research Associates, Inc.

2. Barnewall, M. (1987). "Psychological characteristics of the individual investor," in W. Droms, edition Asset allocation for the individual investor, Charlottesville, Va.: The Institute of Chartered Financial Analysts.

3. Cohn, R., W. Lewellen, R. Lease, and G. Schlarbaum. (1975). "Individual investor risk aversion and investment portfolio composition," Journal of Finance, 30 (2), 605-620.

4. Filbeck, G. and L.Smith. (1996). "Learning styles, teaching strategies, and predictors of success for students in corporate finance," Financial Practice and Education, 6 (1, Spring/Summer), 74-85.

5. $\quad$ Filbeck, G., P. Hatfield, and P.Horvath. (2005). "Risk aversion and personality type," Journal of Behavioural Finance, 6(4), 170-180.

6. $\quad$ Friend, I. And M. Blume. (1975). "The demand for risky assets," American Economic Review, 65, 900-922.

7. Hair, Joseph F., Ralph E. Anderson, and Ronald L. Tatham, 1987, Multivariate Data Analysis with Readings, $2^{\text {nd }}$ ed., Macmillan, New York.

8. Keirsey, D. and M. Bates. (1978). Please understand me, Del Mar, CA: Prometheus Nemisis Books.

9. Lawrence, G. (1994). People types and tiger stripes, Gainsville, FL, Center for Application of Psychological Type, $3^{\text {rd }}$ Edition.

10. Lease, R., W. Lewellen, and G. Schlarbaum. (1974). "The individual investor, attributes and attitudes," Journal of Finance, 29 (2), 413-433.

11. McCaulley, M. (1976), The Myers-Briggs Type Indicator and the teaching learning process, Gainsville, FL, Center for Application of Psychological Type.

12. Myers, I. (1979). Type and teamwork, Gainsville, FL, Center for Application of Psychological Type.

13. Myers, I. (1980), Gifts differing, Palo Alto, CA, Consulting Psychological Press.

14. Myers, I. and M. McCaulley (1998) Manual: A guide to the development and use of the Myers-Briggs Type Indicator, Third Edition, Palo Alto, CA, Consulting Psychological Press.

15. Riley, W. and V. Chow. (1992). "Asset allocation and individual risk aversion," Financial Analysts Journal, 48 (6), 32-37.

16. Rummel, R. J., 1970, Applied Factor Analysis, Northwestern University Press, Evanston, IL.

17. Schooley, Diane and Debra Worden. (1999). "Investors' asset allocations versus life-cycle funds," Financial Analysts Journal, 55 (5), 37-43.

18. Siegal F. and J. Hoban, Jr. (1982). "Relative risk aversion revisited," Review of Economics and Statistics, 64, 481-487. 


\section{EXHIBIT 1}

\section{Dimensions Measured by the Myers-Briggs Type Indicator}

\author{
Preferences \\ for focusing \\ attention
}

Preferences
for
acquiring
information

Preferences

for making decisions

\section{Preferences \\ for \\ orientation \\ to the outer world}

Extroversion (E) - Individuals

focus attention on the outer world

of people and things. They draw energy

from interacting and being engaged, and so learn most effectively when they are engaged in activity.

Sensing (S) - Individuals focus on the concrete aspects of a situation and value what can be seen, touched, felt, smelled, or heard. They tend to be practical minded, concerned with details and facts, and have greater acceptance of what is given.

Thinking (T) - Individuals focus on objective decision making based on a desire for fairness. They seek logic in their analysis of situations, desire situation, to achieve objectivity, and prefer to discover what may be wrong in situations that arise.

Judging ( $\mathbf{J})$ - Individuals focus on leading a life that is organized and orderly, seek closure, prefer control over their lives, and plan accordingly.
Introversion (I) - Individuals focus attention on their inner world. They draw energy from internal reflection, and so learn best through reflecting and understanding the context of a problem before being engaged.

Intuition (N) - Individuals focus on the abstract, and value relationships not immediately recognizable to the physical senses. They strive to understand the "big picture" and are interested in change and future possibilities.

Feeling (F) - Individuals focus on subjective decision making based on a desire for harmony. They consider impacts on people in their analysis of a to work prefer to affirm what is right with situations, and are more likely to offer appreciation and sympathy.

Perceiving (P) - Individuals focus on leading a life that is flexible and spontaneous; they seek to keep decisions open and prefer to adapt to situations rather than control them.

Source: Filbeck and Smith (1996) 


\section{EXHIBIT 2}

Section 1

\section{Return Requirement Questionnaire}

In this questionnaire you are asked to establish the purpose for which your investment or investments will be used. This section establishes your estimates of your anticipated needs from the portfolio, when you expect to begin using the benefits from the portfolio, how much you will be initially investing, how much and how frequently you anticipate making additional contributions. There are a few additional questions for background purposes.

Please note that you are asked to provide estimates. If you do not know how much you will need, for instance, please provide your best guess.

Background:

A What is your approximate net worth?

B. What is your approximate annual income?

C. Do you consider yourself a sophisticated investor?

D. Are you married?

E. How many dependents do you have?

F. What was your age at your last birthday?

G. What is your highest level of formal education?
$\$$

$\$$

$\$$

Years/Months

A. When do you expect to need the funds from this portfolio?

$\$$

C. If you will be making periodic contributions to this portfolio, how often will you be contributing?

D. How much will you be contributing each time?

$\$$

E. How much do you need at maturity?
$\$$ 


\section{Section 2}

\section{Risk Tolerance Questionnaire}

In section one, we determined your future cash needs from your portfolio. In this section you will begin to determine the

amount of risk you are willing to accept in order to meet those needs. Our objective will then be to construct a portfolio

of assets that reflects these acceptable risks as closely as possible.

As was the case with the return questionnaire these are your estimates provided as you see them now. There are no wrong answers. It is not necessary to be precise. Just answer as closely as you can.

Given, in any investment in which the benefits are to be realized in the future, there are real chances positive odds, or positive probabilities of experiencing one of all possible returns from zero to as high as you care to count. The odds at both extremes may be very low, but are not zero.

\section{For Example:}

For your requirement of $\$$ f for the purpose of:____ in_____years;

Please choose your response to the questions below from these choices:

about $0 \%, 10 \%, 20 \%, 30 \%, 40 \%, 50 \%, 60 \%, 70 \%, 80 \%, 90 \%$, about $100 \%$

What are the highest odds, chances or probabilities that you are willing to take or assume that you will have:

Nothing available to meet the above requirement $\%$

If you would be willing to experience having nothing available for your objective one time out of ten, your response would be: $10 \%$. If your tolerance would be one in one-hundred at most your response would be $1 \%$. If you would be comfortable with having nothing available one in one thousand times your response would be $0.1 \%$ and so on.

\section{Please Turn The Page And Begin.}


Please choose your response to the questions below from these choices:

about $0 \%, 10 \%, 20 \%, 30 \%, 40 \%, 50 \%, 60 \%, 70 \%, 80 \%, 90 \%$, about $100 \%$

What are the highest odds, chances or probabilities that you are willing to take or assume that you will have:

$\$ \quad 0 \quad$ [Nothing $(\mathbf{0 \%})]$ to meet the above requirement $\%$

What are the highest odds, chances or probabilities that you are willing to take or assume that you will have:

$\$ \ldots$ [One fourth $(\mathbf{2 5 \%})]$ or less to meet the requirement

(Must be greater than your prior response)

What are the highest odds, chances or probabilities that you are willing to take or assume that you will have:

$\$[$ [One half $(\mathbf{5 0 \%})]$ or less to meet the requirement

(Must be greater than your prior response)

What are the highest $\underline{\text { odds, chances or probabilities }}$ that you are willing to take or assume that you will have:

$\$$ [Three fourths $(\mathbf{7 5 \%})]$ or less to meet the requirement $\%$

(Must be greater than your prior response)

What are the highest odds, chances or probabilities that you are willing to take or assume that you will have:

$\$[$ [All $(\mathbf{1 0 0 \% )}]$ or lessto meet the requirement $\%$

(Must be greater than your prior response)

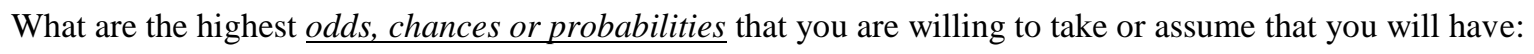

$\$$ $\mathbf{( 1 2 5 \% )}$ or less to meet the requirement $\%$

(Must be greater than your prior response)

What are the highest odds, chances or probabilities that you are willing to take or assume that you will have:

$\$$ $(\mathbf{1 5 0 \%})$ or less to meet the requirement

(Must be greater than your prior response)

What are the highest $\underline{\text { odds, chances or probabilities }}$ that you are willing to take or assume that you will have:

$\$$

(Must be greater than your prior response)

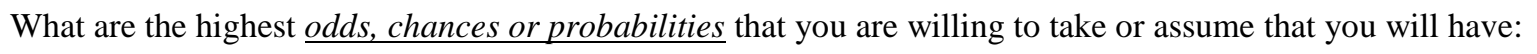

$\$$ $\%$

(Must be greater than your prior response) 


\section{EXHIBIT 3}

\section{Risk Tolerance Survey}

Please indicate your agreement to each of the following statements/scenarios by placing a check mark $(\sqrt{ })$ in the appropriate column.

\begin{tabular}{|c|c|c|c|c|c|}
\hline Question & $\begin{array}{l}\text { Strongly } \\
\text { Agree }\end{array}$ & Agree & Neutral & Disagree & $\begin{array}{l}\text { Strongly } \\
\text { Disagree }\end{array}$ \\
\hline $\begin{array}{l}\text { 1. I feel I have adequate knowledge to develop an } \\
\text { investment portfolio for myself. }\end{array}$ & & & & & \\
\hline $\begin{array}{l}\text { 2. I prefer investments that experience little volatility } \\
\text { (few ups and downs) and am willing to accept the lower } \\
\text { returns these investments may make. }\end{array}$ & & & & & \\
\hline $\begin{array}{l}\text { 3. If the market declines sharply, I would tend to sell } \\
\text { my riskier investments and buy safer investments. }\end{array}$ & & & & & \\
\hline $\begin{array}{l}\text { 4. I would be willing to invest in a stock or mutual fund } \\
\text { based on a brief conversation with a friend or family } \\
\text { member who made a recommendation. }\end{array}$ & & & & & \\
\hline $\begin{array}{l}\text { 5. You are in Atlantic City and are down } \$ 500 \text {. You } \\
\text { have the opportunity to take a bet which gives you a } 50 \\
\text { percent chance of coming out debt-free, and a } 50 \text { percent } \\
\text { chance of being } \$ 1,000 \text { down. Respond to the following } \\
\text { statement: I would be willing to take the bet. }\end{array}$ & & & & & \\
\hline $\begin{array}{l}\text { 6. You are in Atlantic City and are up } \$ 500 \text {. You have } \\
\text { the opportunity to take a bet which gives you a } 50 \\
\text { percent chance of coming home with } \$ 1,000 \text { and a } 50 \\
\text { percent chance of coming home with nothing. Respond } \\
\text { to the following statement: I would be willing to take the } \\
\text { bet. }\end{array}$ & & & & & \\
\hline $\begin{array}{l}\text { 7. I believe that I am better than half of the population in } \\
\text { my ability to predict outcomes of situations. }\end{array}$ & & & & & \\
\hline $\begin{array}{l}\text { 8. I believe that a good investment is a company that } \\
\text { has recently experienced amazing growth and whose } \\
\text { returns have recently been impressive. }\end{array}$ & & & & & \\
\hline $\begin{array}{l}\text { 9. I believe that a good investment is a company that } \\
\text { has recently experienced a steep decline in price due to } \\
\text { adverse news of current firm conditions. }\end{array}$ & & & & & \\
\hline $\begin{array}{l}\text { 10. A good company makes for a good stock } \\
\text { investment. }\end{array}$ & & & & & \\
\hline $\begin{array}{l}\text { 11. I would feel safer investing in stocks that pay } \\
\text { dividends over ones that do not, even if the total return } \\
\text { to both stocks would be equal. }\end{array}$ & & & & & \\
\hline $\begin{array}{l}\text { 12. I would enjoy taking risks in assembling a stock } \\
\text { portfolio. }\end{array}$ & & & & & \\
\hline $\begin{array}{l}\text { 13. I would prefer to invest in certificates of deposit and } \\
\text { bonds because they are safer. }\end{array}$ & & & & & \\
\hline $\begin{array}{l}\text { 14. I would be willing to consider adding individual } \\
\text { stocks to my portfolio which may be very risky by } \\
\text { themselves, if they would help to better diversify my } \\
\text { portfolio. }\end{array}$ & & & & & \\
\hline
\end{tabular}

